\title{
Postmenopausal and Senile Osteoporosis : Current Concepts of Etiology and Treatment
}

\author{
B. LAWRENCE RIGGS
}

\author{
Endocrine Research Unit, Division of Endocrinology / Metabolism \\ and Internal Medicine, Mayo Clinic and Mayo Foundation, \\ Rochester, Minnesota 55901
}

\begin{abstract}
Synopsis
Postmenopausal osteoporosis and senile osteoporosis are heterogeneous disorders that appear to be caused by several nonhormonal and hormonal factors. Of nonhormonal factors, age-related bone loss, the degree of bone density achieved in young adult life, and dietary intake and absorption of calcium appear to be important. Hormones that may be important in pathogenesis are parathyroid hormone (PTH), estrogen, $1,25(\mathrm{OH})_{2} \mathrm{D}$, and possibly calcitonin. Postmenopausal estrogen deficiency accelerates bone loss by increasing responsiveness of bone to endogenous PTH. The resultant increase in release of calcium from bone is associated with normal or low values for serum immunoreactive PTH (iPTH) (except for a subset of $15 \%$ of the total which have high values and appear to represent a separate population). Some evidence suggests that subnormal calcium absorption, which is a common finding in postmenopausal osteoporosis and which may contribute to negative calcium balance, is caused by decreased conversion of $25-\mathrm{OH}-\mathrm{D}$ to $1,25(\mathrm{OH})_{2} \mathrm{D}$. Treatment of osteoporosis with either sex steroids (by antagonizing the effect of PTH on bone resorption) or orally administered calcium with or without vitamin D (by decreasing PTH secretion) decreases bone resorption. Long-term therapy with these agents, however, decreases bone formation; thus, bone loss is only arrested or slowed. Although combined therapy with fluoride and calcium stimulates bone formation and appears to be capable of increasing bone mass, its long-term safety and efficacy in decreasing the the occurrence of fractures remain to be demonstrated.
\end{abstract}

The common forms of primary osteoporosis, sometimes called postmenopausal and senile osteoporosis, occur in middleaged or older persons of either sex but are more frequent and severe in women than in men. In contrast to secondary osteoporosis, there is no recognizable associated disease known to affect bone metabolsm.

Postmenopausal osteoporosis and senile osteoporosis are serious health problems, causing considerable morbidity because of fractures. The diseases symptomatically affect an estimated 4 million older Ameri-

Received October, 1, 1978. cans and cause an estimated 700,000 new fractures yearly (Lutwak and Whedon, 1963; Iskrant and Smith, 1969). The incidence of fracture of the proximal femur in women doubles each decade after ago 60 years (Alffram, 1964). Based on currently available epidemiologic data, the economic cost of hip fractures in the United States can be estimated to approximate $\$ 1$ billion annually (about 200 billion Japanese yen).

Osteoporosis may be even more common in Orientals than in Americans. In 1966, Nordin reported on international patterns of osteoporosis. He found that the incid- 
ence of osteoporosis, assessed by radiolucency on spinal roentgenograms, in women older than age 45 eyears was $30 \%$ in America but $60 \%$ in Japan.

In the ensuing 37 years since Albright, Smith and Richardson (1941) clearly defined the syndromes of postmonopausal and senile osteoporosis, progress in elucidating the cause and in developing effetive treatment has been slow. Much more has been accomplished during the last decade, however, largely because of the development of more sensitive methods (such as raidocalcium kinetic studies, quantitative bone morphology, bone densitometry, and radioimmunoassay of calcitropic hormones) and better understanding of factors controlling bone and mineral metabolism.

Space does not permit a comprehensive review of the numerous investigative studies relating to osteoporosis. Instead, I will focus this report mainly on studies done by our group at the Mayo Clinic and Mayo Foundation. A number of colleagues have been participants and collaborators in these studies. In particular, I would like to acknowledge Drs. C. D. Arnaud, J. C. Gallagher, H. Heath IIII, D. L. Hoffman, J. O. Jowsey, and P. J. Melly of the Mayo Clinic and Mayo Foundation and Dr. H. F. DeLuca of the University of Wisconsin. The reader is referred to the original articles for complete details of these studies and for a more comprehensive review of related work by others.

\section{Pathology}

The pathologic abnormality in osteoporosis is an absolute decrease in the amount of bone to a level that is incapable of maintaining the structural integrity of the skeleton, or, as Dr. Fuller Albright succinctly put it, "there is too little bone." The bone that remains is morphologically normal. Bone loss is proportionately greater in areas of the the skeleton which contain relatively large amounts of trabecular bone and which are subject to prime load-bearing; this accounts for the presenting features of the/or the vertebrae, fractures of the proximal femur, and fractures of the distal radius.

For bone to be lost, obviously the rate of bone resorption must exceed that of formation. A lively controversy exists, however, about whether the primary abnormality is an absolute increase in bone resorption, an absolute decrease in bone formation, or some combination thereof. Time does not permit a review of the details of this controversy. suffice it to say, it is my opinion that the menopause accelerates the rate of bone resorption and that this is superimposed on an age-related decrease in the rate of bone formation. In any event, there is a disruption of the usually tightly coupled processes of resorption and formation. Obviously, even a "normal" rate of resorption is abnormal when the rate of formation decreases, because normally homeostatic mechanisms should decrease the rate of resorption to approximate that of formation.

\section{Etiology}

Primary osteoporosis should be considered as a multifactorial, heterogenous disorder. Both nonhormonal and hormonal and hormonal factors appear to contribute to bone loss.

\section{Normal Factors}

Age-Related Bone Loss. -After attaining maximal skeletal mass in young adult life, all persons appear to lose bone with aging. After age 50 years, this loss is approximately $10 \%$ per decade in women and $5 \%$ per decade in men (Newton-John and Morgan, 1968). Age-related bone loss probably a summation of several factors, 
which, particulary in the later decades of life, include senile atrophy of bone cells.

Initial Bone Density.-In the United States, it has been appreciated for some time that symptomatic osteoporosis is most common in white women and least common in black men. Since the early work of Trotter, Broman, and Peterson (1960), it has been known that maximal bone density achieved in young adult life is least in white women, greatest in black men, and intermediate in white men and black women. Inasmuch as the rate of bone loss with aging in each of these four race and sex subgroups was found to be similar, initial bone density appears to be a major determinant of eventual bone density in later life and, consequently, of individual susceptibillty to osteoporosis (Newton-John and Morgan, 1968). Although definitive studies have not been done, Oriental women may be similar to white women in this respect and may have a relatively low initial bone density. Also, within the same race and sex subgroup, there appears to be a gaussian distribution of values for initial bone density. Smith et al. (1973) have shown that individual values for bone density are, in part, genetically determined. As age-related bone loss ensues, individuals with the lowest initial levels of bone density would be at the greatest risk for having bone density decrease to the level at which spontaneous fractures occur (Fig. 1).

Nutritional Factors. - If the nutritioual requirement for calcium is not maintained because of poor dietary intake or absorption, calcium must be witndrawn from the skeleton because no other long-term reservior of calcium exists. This sequence has been clearly demonstrated in experimental animals. Recent work by Heaney, Recker, and Saville (1977) suggests that this also may occur in humans. These workers studied metabolic balance for calcium in a group of perimenopausal female volunteers.
They found that dietary calcium intake and calcium balance were positively related. The zero intercept-that is, the level of dietary calcium required to prevent negative calcium balance-for this group was $1,241 \mathrm{mg} / \mathrm{day}$. This value is well above the average intake of $700 \mathrm{mg} /$ day for postmenopausal American women. Thus, dietary calcium intake may be a more important contributing factor to bone loss than previously has been recognized. If so, this would be paticularly relevant to the Japanese population who, based on the World Health Organization's survey in

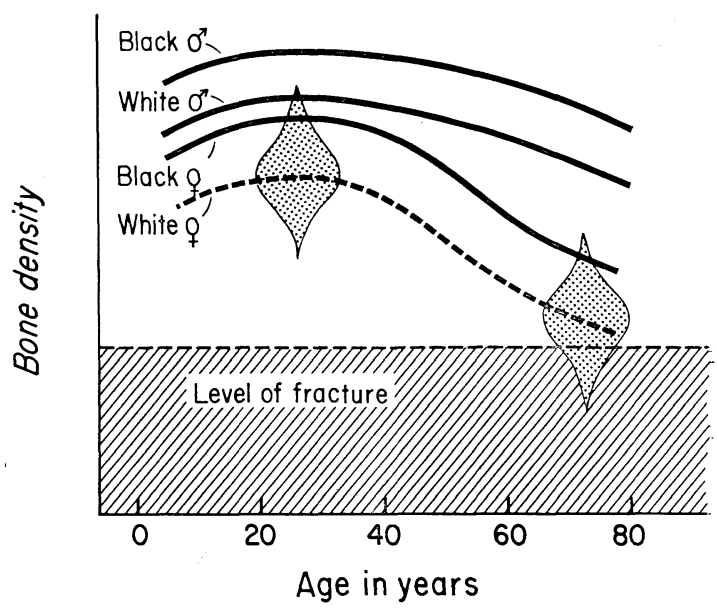

Fig. 1. Diagrammatic illustration of effects of heredity, race, sex, and age on variations in bone density. Initial bone density achieved at end of adolescent growth spurt is greatest in black males, is intermediate in black females and white males, and is least in white females. Also, within each race and sex subgroup, there is a gaussian distribution of bone density values (shown here only for white females by dotted bell-shaped distribution figure). As age progresses, mean bone density (given by lines) decreases. Absolute decrease with age is similar in each race, although menopause accelerates bone loss in females. Thus, eventual bone density reached in old age may be related to initial bone density achieved in young adult life. White females who have values for initial bone density in lower part of distribution will be at particular risk for having bone density decrease to level at which spontaneous fractures occur (cross-hatched area). 
1962 , one of the lowest in the world (Nordin, 1976).

Whether a high dietary phosphate intake predisposes to development of esteoporosis remains to be established.

\section{Hormonal Factors}

Parathoroid Hormone. - Because parathyroid hormone (PTH) is a major hormonal regulator of both calcium homoestasis and bone resorption, accurate assessment of serum immunoreactive PTH (iPTH) is essential for any comprehensive understanding of overall pathogenesis. The serum iPTH concentration in primary osteoporosis has been reported by various investigators to be low, normal, or high. We measured serum iPTH Using two radioimmunoassay systems (Arnaud, Tsao and Littledike, 1971), one directed primarily against determinants on the $\mathrm{COOH}$-terminal ( $\mathrm{GP}-1 \mathrm{M}$ ) and one directed primarily against determinants on the $\mathrm{NH}_{2}$-terminal $(\mathrm{CH}-14 \mathrm{M})$ of the $\mathrm{PTH}$ molecule. When antiserm GP-1 M was used, the serum iPTH concentration did not differ significantly between osteoporotic and age-mached normal postmenopausal women. There was a highly significant

Table 1. Serum iPTH ( $\mu l$ eq/ml, Mean $\pm \mathrm{SE})$

\begin{tabular}{lccc}
\hline \multicolumn{1}{c}{ Subjects } & \multicolumn{3}{c}{ Specificity } \\
\multicolumn{1}{c}{ Status } & No. & COOH-terminal & $\mathrm{NH}_{2}$-terminal \\
\hline Osteoporosis* & 47 & $25.1 \pm 1.8$ & $69.9 \pm 14.2$ \\
Age-matched & 79 & $22.4 \pm 0.9$ & $127.2 \pm 9.2$ \\
normals & & NS & $<0.001$ \\
\hline
\end{tabular}

* Seven patients $(15 \%)$ had increased values. decrease in the serum iPTH level, however, when assessed by antiserum $\mathrm{CH}-14 \mathrm{M}$. With respect to individual values, 7 of 47 patients $(15 \%)$ had increased values with one of the other of the antisera and, thus, appeared to represent a separate population from the larger group (Riggs et al., 1973a). These results are summarized in Table 1. We interpret these findings as indicating that the majority of American patients with osteoporosis have either normal or decreased PTH secretion.

The observation that serum iPTH concentration are normal or decreased in osteoporpsis does not preclude a permissive or sustaining role of $\mathrm{PTH}$ in maintaining bone resorption; in fact, such a role seems probable. Humans who had undergone parathyroidectomy failed to demonstrate the expected age-related loss of cortical bone (Hossain, Smith, and Nordin, 1970). As shown in Table 2, therapeutic measures that decrease serum iPTH concentration in osteoporosis decrease bone-resorption surfaces, as assessed by microradiography, and vice versa. After 3 to 4 months of treatment with orally administered calcium and vitamin D, values for both serum iPTH and bone-resorption surfaces decreased significantly (Riggs et al., 1976). After treatment with an orally administered phosphate supplement, a small increase in serum iPTH concentration was associated with a significant increase in bone-resorption surfaces (Goldsmith et al., 1976). After 1 to 3 months of treatment with calcitonin (CT), serum iPTH values increased

Table 2. Postmenopausal Osteoporosis: Effect of Therapy

\begin{tabular}{|c|c|c|c|c|c|}
\hline \multirow[t]{2}{*}{ Program } & \multirow[t]{2}{*}{ No. of patients } & \multicolumn{2}{|c|}{$\begin{array}{c}\text { iPTH } \\
(\mu l \text { eq } / \mathrm{m} l)\end{array}$} & \multicolumn{2}{|c|}{$\begin{array}{l}\text { Bone resorption } \\
\text { (\% total surface) }\end{array}$} \\
\hline & & Before & After & Before & After \\
\hline Vitamin D and calcium, orally & 18 & 30 & $22^{*}$ & 12.1 & $6.3^{*}$ \\
\hline Phosphate, orally & 9 & 16 & 23 & 10.9 & $19.4^{*}$ \\
\hline Calcitonin & 5 & 22 & $39 *$ & 11.8 & 14.8 \\
\hline
\end{tabular}

$* \mathrm{p}<0.05$. 
significantly, presumably because of the hypocalcemic effect of CT. This was associated with a small increase in boneresorption surfaces. The increase in serum iPTH concentration correlated positively with the increase in bone-resorption surfaces (Jousey et al., 1971a).

Sex Steroids.- Recently, objective measurements of bone density (Lindsay et al., 1977 ; Recker, Saville and Heaney, 1977) have validated the long-held theory of Albright et al. (1941) that the menopause accelerates bone loss in women. We have studied the mechanism of the estrogen effect. Seventeen osteoporotic women underwent trephine biopsy of the iliac crest and metabolic studies before and after short-term $\left(2 \frac{1}{2}\right.$ to 4 months $)$ treatment with conjugated equine estrogens (Riggs et al., 1969, 1972) Bone-formation and boneresorptiod surfaces were assessed by quantitative microradiography (Jowsey et al., 1965) (Table 3). Before treatment, boneresorption surfaces were significant!y above the normal range whereas formation surfaces were normal. After short-term therapy, bone-resorption surfaces decreased significantly but bone-formation surfaces did not change. Also, the urinary hydroxyproline leval, an index of bone resorption, decreased significantly. The apparent decrease in bone resoption with no change in bone formation explains the positve calcium balance that has previously been reported after short-term estrogen treatment (Albright et al., 1941). The serum calcium concentration decreased and the serum iPTH value increased significantly; however, these changes occurred within the normal range. The decrease in serum and urine calcium levels can be attributed to inhibition of bone resorption. In these patients, PTH secreton appeared to be appropriate because the expected increase in iPTH occurred in response to the estrogeninduced decrease in serum calcium concentration. It is well known that serum iPTH and serum calcium are negatively correlated. In contrast to the normal secretory response of parathyroid glands, however, the biologic effectiveness of PTH was clearly decreased by estrogen replacement therapy because higher values for serum iPTH were assciated with the lower values for both bone-resorption surfaces and urinary hydroxyproline excretion. These findings strongly suggest that estrogen exerts its effect by decreasing responsiveness of bone to endogenous $\mathrm{PTH}$, a proposal previously made by Heaney (1965) and by Jasani et al. (1965). This effect of estrogen could occur by direct inhibition of osteoclast fuction, by inhibition of osteoclast induction from precursor cells in bone mesenchyme, or by both mechanisms. After longterm treatment (26 to 42 months), in nine patients there was a highly significant $(\mathrm{p}<0.001)$ decrease in bone-forming surfaces to $0.6 \pm$

Table 3. Postmenopausal Osteoporosis: Effect of Estrogen Therapy (10 to 16 Weeks)

\begin{tabular}{|c|c|c|c|c|}
\hline & No. of patients & $\begin{array}{l}\text { Before treatment } \\
\quad(\text { mean } \pm S E\end{array}$ & $\begin{array}{l}\text { After treatment } \\
(\text { mean } \pm S E)\end{array}$ & $\mathbf{P}$ \\
\hline \multicolumn{5}{|c|}{ Microradiographe (\% surfaces): } \\
\hline Bone forming & 17 & $3.3 \pm 0.5$ & $3.3 \pm 0.6$ & NS \\
\hline Bone-resorbing & 17 & $13.0 \pm 0.8$ & $7.2 \pm 0.6$ & $<0.001$ \\
\hline \multicolumn{5}{|l|}{ Serum: } \\
\hline $\mathrm{Ca}(\mathrm{mg} / \mathrm{d} l)$ & 17 & $9.60 \pm 0.07$ & $9.14 \pm 0.05$ & $<0.001$ \\
\hline iPTH $(\mu l \mathrm{eq} / \mathrm{m} l)$ & 8 & $24.7 \pm 2.0$ & $34.5 \pm 3.6$ & $<0.01$ \\
\hline \multicolumn{5}{|l|}{ Urine: } \\
\hline $\mathrm{Ca}(\mathrm{mg} / \mathrm{day})$ & 12 & $144 \pm 20$ & $81 \pm 13$ & $<0.01$ \\
\hline Hydroxyproline (mg/day) & 12 & $25.5 \pm 1.7$ & $19.9 \pm 2.2$ & $<0.05$ \\
\hline
\end{tabular}


$0.2 \%$. These values for bone-formation surfaces are almost as low as those observed patients with severe hypercortisonism.

In many metabolic bone disorders characterized by primary increase in resorption, there is a secondary increases in the formation; in osteoporosis, this compensation is lacking. The secondary decrease in bone formation after long-term therapy suggests that an inherent abnormality in osteoblastic function or differentiation exists in osteoporosis; this abnormality is masked in the pretreatment period by the increase in bone resorption but becomes apparent when bone resorption is decreased by therapy. The delayed decrease in formation after longterm treatment with estrogen prevents maintenance of the positive calcium balance observed after short-term therapy. Consequently, the best that can be expected from long-term therapy in osteoporosis is to arrest or to decrease the progression of bone loss.

The monopause, however, is an incomplete explanation for the development of osteoporosis. All postmenopausal women are are estrogen-deficient, yet osteoporosis develops in only some of them. Accelerated bone loss could result from a greater than normal postmenopausal reduction in residual sex hormone production in women with osteoporosis. We have measured serum gonadotropins and sex steroids in a large group of osteoporotic patients (Riggs et al., 1937b; Bartizal et al., 1976) and have not found significant differences from agematched normal postmenopausal women
(Table 4). In contrast to these findings, Lindsay, Coutts, and Hart (1977) reported a significant correlation between serum estradiol and fasting urinary calcium levels in postmenopausal women. Also, Marshall, Crilly, and Nordin (1977) reported that, although there was a large overlap of values, serum androstenedione and estrone levels were significantly lower in esteoporotic than in normal postmenopausal women; however, the difference between osteoporotic postmenopausal women was less than $10 \%$ of the normal premenopausal mean. Although we cannot exclude the possibility that small differences in sex steroids contribute to bone loss, it seems unlikely that this is the sole determinant of postmenopausal osteoporosis.

Theoretically, osteoporotic subjects could have similar postmenopausal levels of estrogen but decreased responsiveness of estrogen-sensitive tissues. We were unable to demonstrate a molecular defect in estrogen action, however, because the concentration of specific cytosolic estrogen receptors in biopsy tissue from the uterine cervix of postmenopausal osteoporotic and nonosteoporotic women was similar (unpublished data).

Calcitonin. - Although its physiologic role in man has been questioned, CT is an effective inhibitor of bone resorption; thus, impaired production of CT could be a contributing factor that accelerates bone loss. Heath and Sizemore (1977), from our group, used a sensitive radioimmunoassay to study the concentrations of $\mathrm{CT}$ in

Table 4. Postmenopausal Women: Mean Levels of Sex Steroids

\begin{tabular}{lrrrr}
\hline Determination* & No. of subjects & Normal & Osteoporosis & P \\
\hline Serum : & 47 & 30 & 30 & NS \\
LH $(\mu \mathrm{g} \mathrm{LER} / \mathrm{d} l)$ & 47 & 189 & 202 & NS \\
FSH $(\mu \mathrm{g} \mathrm{LER/d} l)$ & 27 & 50 & 52 & NS \\
Testosterone $(\mathrm{ng} / \mathrm{d} l)$ & 47 & 50 & 44 & NS \\
Estrogen $(\mathrm{pg} / \mathrm{m} l)$ & & & & \\
\hline
\end{tabular}

* $\mathrm{LH}=$ luteinizing hormone; $\mathrm{FSH}=$ follicle-stimulating hormone. 
plasma in 45 normal adults, ages 20 to 45 years. The concentration of plasma immunoreactive CT (iCT) was twice as high in the men as in the women. Furthermore, after intravenous administration of pentagastrin, a potent CT secretagogue, plasma iCT concentration increased in 8 of 10 men but in only 1 of 14 women. Thus, a lifelong relative deficiency of $\mathrm{CT}$ in some women may predispose to abnormal increases in bone resorption. This may be of little importance until after the menopause, however, when the effect of estrogen in imposing $\mathrm{PTH}$-induced bone resorption is lost.

Vitamin D Endocrine System. - The vitamin $\mathrm{D}$ endocrine system currently is believed to be the most important regulator of intestinal calcium absorption. Boyle, Gray, and DeLuca (1971) have shown in rats that the adaptive increase in intestinal calcium absorption in response to low calcium intake is mediated by increased production of the physiologically active from of vitamin D, $1,25(\mathrm{OH})_{2} \mathrm{D}$. Studies in man have shown that this adaptive increasi in intestinal absorption is the principal mechanism that prevents negative calcium balance when dietary calcium intake is decreased (Malm, 1963).

Many investigators have shown that intestinal calcium absorption decreases with aging and is even lower than normal in patients with osteoporosis. The decrease is of sufficient magnitude that it could contribute to negative calcium balance in osteoporotic and in elderly persons, Using the double-isotope technique (100 $\mathrm{mg}$ calcium carrier), we found that calcium absorption was less than normal $(\mathrm{p}<0.001)$ in postmenopausal women when either ago or dietary calcium intake was used as a covariable (Gallagher et al., 1976). The abnormality in absorption was greatest in those osteoporotic patients who had relatively low dietary calcium intakes, which suggests impaired intestinal adaptation. In
95 normal subjects ( 78 females and 17 males, ages 30 to 90 years) whom we studied, calcium absorption correlated inversely with dietary calcium intake in the nonelderly subjects (younger than 65 years), whereas in the elderly subjects (65 years old or older) this correlation was lacking (Gallagher, Riggs, and DeLuca, in press). Thus, both in patients with postmenopausal osteoporosis and in elderly subjects, there was impairment of calcium absorption and loss of adaptation; however, these abnormalities were more pronounced in the osteoporotic patients.

Using radioligand assays, we measured vitamin D metabolites in 17 women with postmenopausal osteoporosis and 17 agematched normal postmenopausal controls (Gallagher et al., 1976). Serum 25-OH-D was similar in both, an indication of normal vitamin $\mathrm{D}$ nutrition and absorption. Serum $1,25(\mathrm{OH})_{2} \mathrm{D}$ was significantly lower, however, which suggests impaired conversion of $25-\mathrm{OH}-\mathrm{D}$ to $1,25(\mathrm{OH})_{2} \mathrm{D}$. Although the mean decrease in serum $1,25(\mathrm{OH})_{2} \mathrm{D}$ was only about $25 \%$, we believe that this could account for most or all of the decrease in calcium absorption, because calcium absorption was significantly correlated with serum $1,25(\mathrm{OH})_{2} \mathrm{D}$ within the normal range and impaired calcium absorption in the osteoporotic subjects was corrected by administration of a physiologic dose (0.4 $\mu \mathrm{g} /$ day) of synthetic $1,25(\mathrm{OH})_{2} \mathrm{D}_{3}$. Studies in experimental animals have demonstrated that convertion of $25-\mathrm{OH}-\mathrm{D}$ to $1,25(\mathrm{OH})_{2} \mathrm{D}$ is facilited by $\mathrm{PTH}$, hypophosphatemia, and estrogen (DeLuca, 1976; Tanaka, Castillo, and DeLuca, 1976). In these patients, the mean serum iPTH concentration was normal or low and the serum phosphate level was high. In another group of patients with postmenopausal osteoporosis, we showed that estrogen therapy increased both serum $1,25(\mathrm{OH})_{2} \mathrm{D}$ and calcium absorption (Gallgher et al., 1978a). Thus, the data are consistent with the 
following serum mechanism: estrogen deficiency $\rightarrow$ increased calcium release from bone $\rightarrow$ decreased PTH secretion $\rightarrow$ decreased conversion of $25-\mathrm{OH}-\mathrm{D}$ to $1,25(\mathrm{OH})_{2} \mathrm{D}$ $\rightarrow$ decreased $1,25(\mathrm{OH})_{2} \mathrm{D}$ production $\rightarrow$ decreased 1, $25(\mathrm{OH})_{2} \mathrm{D}$ prodution $\rightarrow$ decreased calcium absorption. As previously mentioned, all postmenopausal women are relatively estrogen-deficient, so it must be postulated that osteoporotic women have either a greater increase in sensivity of estrogen deficiency or a greater increase in sensitivity of bone to PTH in the absence of estrogen.

Although decreased serum $1,25(\mathrm{OH})_{2} \mathrm{D}$ appears to be secondary in factors that normally stimulate the conversion of $25-\mathrm{OH}-\mathrm{D}$ to $1,25(\mathrm{OH})_{2} \mathrm{D}$, the resultant decrease in calcium absorption could contribute to negative calcium balance. Impaired absorption would most likely be harmful in those osteoporotic patients with a low intake of dietary calcium. Resolution of this issue will require long-term metabolic balance studies before and after treatment with physiologic doses of 1,25 $(\mathrm{OH})_{2} \mathrm{D}_{3}$. Our preliminary results of a double-blind controlled study in esteoporotic subjects have shown that, after 6 months of treatment with $0.5 \mu \mathrm{g}$ daily of synthetic $1,25(\mathrm{OH})_{2} \mathrm{D}_{3}$, calcium absorption was incresed and negative calcium balance was reduced in the treated patients, whereas there was no change in patients treated with placebo (Gallgher et al., 1978b).

Although most patients with postmenopausal osteoporosis have a normal or decreased serum iPTH concentration, a small subset have increased values. The cause of the apparent secondary hyperparathyroidism of this subset is unclear. Recently we studied three such patients in detail (Riggs et al., 1978). Although the serum iPTH level was two three times more than the age-adjusted normal mean, serum ionized and total calcium values were in the lower half of the normal range and seum 1, 25-
$(\mathrm{OH})_{2} \mathrm{D}$ was in the low-normal range. Because patients with primary hyperparathyroidism and comparable increase in serum 1, 25( OH $)_{2} \mathrm{D}$ concentrations (Kaplan et al., 1977), values in these patients seem inapporopriately low and are compatible with the hypothesis that the secondary hyperparathyroidism was caused by inadequate conversion of 25-OH-D to $1,25-$ $(\mathrm{OH})_{2} \mathrm{D}$.

Although estrogen affects vitamin D metabolism, we found no precipitous decrease in calcium absorption in normal women at the time of the menopause. Thus, it seems unlikely that the menopause alone could account for the progressive linear decrease in calcium absorption that continues into the 10th decade of life. Moreover, males have a progressive decrease in calcium absorption which is almost as large as that which occurs in postmenopausal women. Horst, Jorgenson, and DeLuca (in press) have directly demonstrated that renal $1 \alpha$-hydroxylase activity decreases with aging in rats, and possibly an analogous mechanism could account for the decrease in calcium absorption in aging humans.

In support of this hypothesis, we found that serum $1,25(\mathrm{OH})_{2} \mathrm{D}$ was significantly lower $(p<0.005)$ in elderly than in nonelderly subjects. Also, in contrast to nonelderly subjects in whom a highly significant correlation between dietary calcium intake aud serum $1,25(\mathrm{OH})_{2} \mathrm{D}$ was present, this correlation was lacking in the elderly subjects (Gallgher et al., 1976). An agerelated primary impairment in metabolism of $25-\mathrm{OH}-\mathrm{D}$ to $1,25(\mathrm{OH})_{2} \mathrm{D}$ could explain our previous finding that serum iPTH concentration incrases with aging (Gallagher et al., 1977). In patients with postmenopausal esteoporosis, serum iPTH concentration also increases with aging, although at any given age it is lower than normal in most patients (Gallagher, Riggs, and DeLuca, in press). These paradoxical observations 
could be reconciled if it is postulated that the most important cause of decreased serum $1,25(\mathrm{OH})_{2} \mathrm{D}$ in postmenopausal osteoporosis during the first 2 decades after the menopause is the previously discussed mechanism induced secondarily by estrogen deficiency. Subsequently, as both normal and osteoporotic subjects advance in age, a primary decrease in the metabolism of $25-\mathrm{OH}-\mathrm{D}$ to $1,25(\mathrm{OH})_{2} \mathrm{D}$ may be superimposed.

Clearly, much work is needed to characterize the various subtypes of osteoporosis, We can be certain, however, that what formerly was called postmenopausal or serine osteoporosis is a heterogeneous disorder and canot be explained completely on the basis of a single etiologic mechanism.

\section{Treatment}

Even after almost 40 years of clinical investigation, unfortunately there still is no completely satisfactory treatment for esteoporosis.

During the last decade, our group has studied several different therapeutic program for osteoporosis, using microradiography of biopsy samples of iliac crest and other methods. All patients had untreated primary osteoporosis and vertebral compression fractures. Most patients were postmenopausal women between the ages of 50 and 75 years.

Three types of response therapy were observed (Table 5). Patients treated with placebo for 6 months had no change in pretreatment values for both remodeling (Gallagher al al., 1978a). Use of CT (Goldsmith et al., 1976), diphosphonate (Jowsey et al., 1971b), and orally administered phosphate (Riggs et al., 1976) produced the first type of response. With use of these agents, the bone-resorbing and bone-forming surfaces remained the same or became worse. Thus, they were judged not to be therapeutically useful. The failure of decrease bone resrption probably was caused by stimulation of endogenous PTH secretion as a result of the hypocalcemic effect of CT. When secondary hyperparathyroidism was prevnted by concurrently administering calcium orally, however, CT therapy appeared to be effective (Jowsey et at., 1978). Use of diphosphonate not only failed to decrease bone resorption but also produced excssive osteoid tissue. Impaired bone minerallzation probably was cased by blocking of the conversion of amorphous calcium phosphate to hydroxyapatite, a phenomenon that has been demonstrated with these compounds in vitro. Oral phosphate therapy increased resorbing surfaces in six of seven patients.

Estrogen (Rigge et al., 1969; Recker, Saville, and Heaney, 1977), synthetic anabolic hormones (Riggs et al., 1969), calcium (Hossain, Smith, and Nordin, 1970), and calcum-CT combined therapy (Jowsey et al., 1978) produced the second type of therapeutic response-their primary effect was to decrease bone resorption. After long-tem treatment (more 6 months) with these agents, however, there was a secondary decrease in bone formation which negated, in part, their initial favorable

Table 5. Postmenopausal Osteoporosis : Response to Therapy

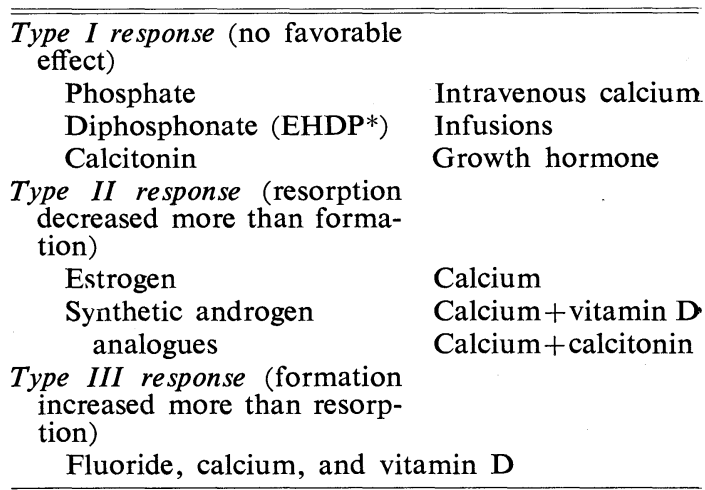

* EHDP=ethane-1-hydroxy-1, 1-diphosphonate. 
effect. This phenomenon probably was related to the well-known coupling between bone resorption and bone formation. After steady-state conditions are reached, a decrease in resorption results obligatorily in a decrease in formation. Thus, it seems likely that these agents can only arrest or slow the progression of bone loss in osteoporosis.

Only combned therapy with fluoride produced the third type of response-an increase in bone-forming surfaces (Jowsey et al., 1972). Supplemental calcium, however, was required to mineralize the newly formed bone and to prevent the increase in resorption that may occur with use of fluoride alone. The mechanism by which fluoride stimulates bone formation is unknown. because fluorohydroxyapatite crystals are larger than those of hydroxyapatite, it is possible that the the flow of piezoelectric current in bone is increased and that this stimulates osteoblasts. Alternatively, the effect may be produced by fluoride-mediated induction of enzymes on bone cells.

Recent studies by several investigators have shown that this program, as we originally predicted (Riggs and Jowsey, 1972), will significantly increse vertebral bone mass. Even thogh increased bone mass should be beneficial, it must be recalled that fluoridic bone has increased crystallinity and decreased elasticity and does not necessarily have the some strength as normal bone (Riggins et al., 1976). Also, we have observed that further vertbral compression fractures occur in one-third of the patients even after up to 6 years of treatment with this program and, although reversible with cessation of fluoride therapy, one-half of the patients will have significant side effects (gastritis, synovitis, painful planter fascitis, and hair loss) (Riggs et al., unpublished data). Thus, the long-term safety and efficacy of combined fluoride therapy remain to be demonstrated, and further studies evaluating the antifracture efficacy of this program are needed before it can be recommended for routine treatment.

\section{References}

Albright, F., P. H. Smith and A. M. Richardson (1941). J. Am. Med. Assoc. 116, 2465.

Alffram, P.-A. (1964). Acta Orthop. Scand. Suppl. $65,1$.

Arnaud, C. D., H. S. Tsao and T. Littledike (1971). J. Clin. Invest. 50, 21.

Bartizal, F. J., C. B. Coulam, T. A. Gaffey, R. J. Ryan and B. L. Riggs (1976). Gynecol. Invest. 7, 330.

Boyle, I. T., R. W. Gray and H. F. DeLuca (1971). Proc. Natl. Acad. Sci. U.S.A. 68, 2131.

DeLuca, H. F. (1976). J. Lab. Clin. Med. 87, 7.

Gallagher, J. C., B. L. Riggs and H. F. DeLuca Clin. Res. (in press).

Gallagher, J. C., B. L. Riggs, J. Eisman, S. B. Arnaud and H. F. Deluca (1976). Clin. Res. 24, 580A.

Gallagher, J. C., B. L. Riggs, A. Hamstra and H. F. DeLuca (1978a). Clin. Res. 26, 415A.

Gallagher, J. C., B. L. Riggs, C. M. Jerpbak and C. D. Arnaud (1977). Clin. Res. 25, 562A.

Gallagher, J. C., B. L. Riggs, K. A. Johnson and H. F. DeLuca (1978b). Program and Abstracts, Annual Meeting, Endocrine Society, 489

Goldsmith, R. S., J. Jowsey, W. J. Dube, B. L. Riggs, C. D. Arnaud and P. J. Kelly (1976). J. Clin. Endocrinol. Metab. 43, 523.

Heaney, R. P. (1965). Am. J. Med. 39, 877.

Heaney, R. P., R. R. Recker and P. D. Saville (1977). Am. J. Clin. Nutr. 30, 1603.

Heath, H., III and G. W. Sizemore (1977). J. Clin. Invest. 60, 1135.

Horst, R. W., N. Jorgenson and H. F. DeLuca Metabolic Bone Dis. Relat. Res. (in press)

Hossain, M., D. A. Smith and B. E. C. Nordin (1970). Lancet 1, 809.

Iskrant, A. P. and R. W. Smith, Jr. (1969). Public Health Rep. 84, 33.

Jasani, C., B. E. C. Nordin, D. A. Smith and I. Swanson (1965). Proc. R. Soc. Med. 58, 441.

Jowsey, J., P. J. Kelley, B. L. Riggs, A. J. Bianco, Jr., D. A. Scholz and J. Gershon-Cohen (1965). J. Bone Jt. Surg. Am. Vol. 47, 785.

Jowsey, J., B. L. Riggs, R. S. Goldsmith, P. J. Kelly and C. D. Arnaud (1971a). J. Clin. Endocrinol. Metab. 33, 752.

Jowsey, J., B. L. Riggs, P. J. Kelly and D. L. Hoffman (1972). Am. J. Med. 53, 43.

Jowsey, J., B. L. Riggs, P. J. Kelly and D. L. Hoffman (1978). J. Clin. Endocrinol. Metab. 47, 633. 
Jowsey, J., B. L. Riggs, P. J. Kelly, D. L. Hoffman and P. Bordier (1971b). J. Lab. Clin. Med. 78, 574.

Kaplan, R. A., M. R. Haussler, L. J. Deftos, H. Bone and C. Y. Pak (1977). J. Clin. Invest. 59, 756.

Lindsay, R., J. R. T. Coutts and D. M. Hart (1977). Clin. Endocrinol. (Oxford) 6, 87.

Lindsay, R., D. M. Hart, J. M. Aitken, E. B. MacDonald, J. B. Anderson and A. C. Clarke (1976). Lancet 1, 1038.

Lutwak, L. and G. D. Whedon (1963). DM Dis. Mon. April, 1.

Malm, O. J. (1963). The Transfer of Calcium and Strontium Across Biological Membranes (edited by R. H. Wasserman). Academic Press, New York, p. 143.

Marshall, D. H., R. G. Crilly and B. E. C. Nordin (1977). Br. Med. J. 2, 1177.

Newton-John, H. F. and D. B. Morgan (1968). Lancet $1,232$.

Nordin, B. E. C. (1066). Clin. Orthop. 45, 17.

Nordin, B. E. C. Calcium, Phosphate and Magnesium Metabolism: Clinical Physiology and Diagnostic Procedures. Churchill Livingstone, Edinburgh, p. 6 (1976).

Recker, R. R., P. D. Saville and R. P. Heaney (1977). Ann. Intern. Med. 87, 649.

Riggins, R. S., R. C. Rucker, M. M. Chan, F. Zeman and J. R. Beljan (1976). Clin. Orthop. 114, 352.
Riggs, B. L., C. D. Arnaud, J. Jowsey, R. S. Goldsmith and P. J. Kelly (1973a). J. Clin. Invest. 52, 181.

Riggs, B. L., J. C. Gallagher, H. F. DeLuca, A. J. Edis, P. W. Lambert and C. D. Arnaud (1978). Mayo Clin. Proc. 53, 701.

Riggs, B. L., S. F. Hodgson, D. L. Hoffman, P. J. Kelly and K. A. Johnson (unpublished data).

Riggs, B. L. and J. Jowsey (1972). Semin. Drug Treat. $2,27$.

Riggs, B. L., J. Jowsey, R. S. Goldsmith, P. J. Kelly, D. L. Hoffman and C. D. Arnaud (1972). J. Clin. Invest. 51, 1659.

Riggs, B. L., J. Jowsey, P. J. Kelly, D. L. Hoffman and C. D. Arnaud (1976). J. Clin. Endocrinol. Metab. 42, 1139.

Riggs, B. L., J. Jowsey, P. J. Kelly, J. D. Jones and F. T. Maher (1969). J. Clin. Invest. 48, 1065.

Riggs, B. L., R. J. Ryan, H. W. Wahner, N.-S. Jiang and V. R. Mattox (1973b). J. Clin. Endocrinol. Metab. 36, 1097.

Smith, D. M., W. E. Nance, K. W. Kang, J. C. Christian and C. C. Johnstton, Jr. (1973). J. Clin. Invest. 52, 2800.

Tanaka, Y., L. Castillo and H. F. DeLuca (1976). Proc. Natl. Acad. Sci. U.S.A. 73, 2701.

Trotter, M., G. E. Broman and R. R. Peterson (1960). J. Bone Jt. Surg. Am. Vol. 42, 50. 